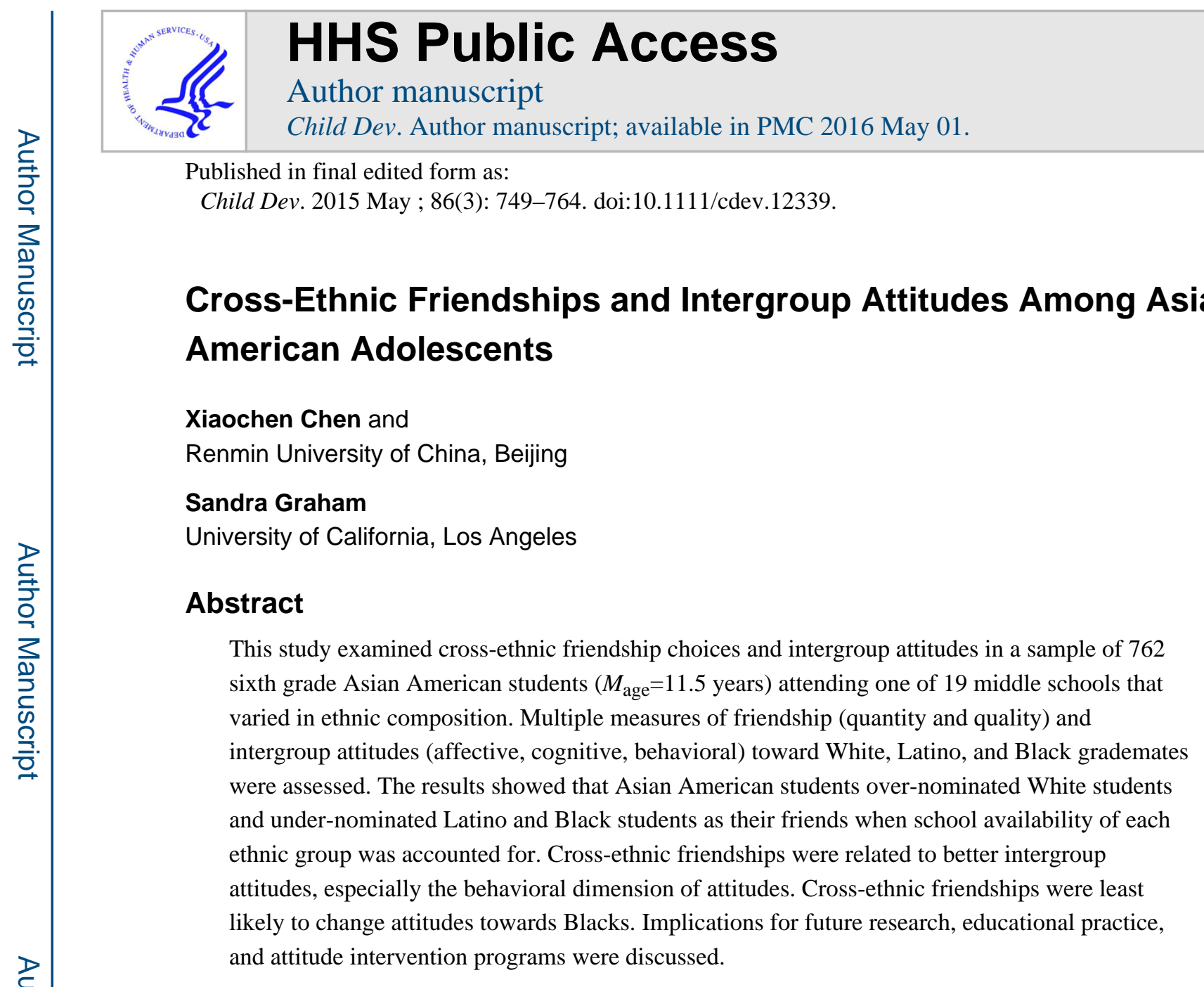

\title{
Keywords
}

cross-ethnic friendships; intergroup attitudes; Asian American adolescents

\begin{abstract}
A substantial body of research has documented the important role of friendships in healthy adjustment throughout the life course (e.g., Hartup \& Stevens, 1999; Reis \& Collins, 2004). Friendships take on added significance in early adolescence when peers and peer groups become more importance in youths' lives (Brechwald \& Prinstein, 2011). Since most adolescents' friendships are formed in school and with the growing ethnic diversity of U.S. public schools (Fry, 2007), friendship researchers have begun to distinguish between sameand cross-ethnic friendships and to examine the unique functions of the cross-ethnic type. For example, recent research has shown that friendships with cross-ethnic peers are associated with better intergroup attitudes (reviewed below), better perceived social competence (Hunter \& Elias, 1999; Lease \& Blake, 2005), stronger leadership skills
\end{abstract}

\footnotetext{
Correspondence concerning this article should be addressed to: Xiaochen Chen, Department of Psychology, Renmin University of China, Beijing, China 100872. xiaochenchen@ ruc.edu.cn.

Xiaochen Chen, Department of Psychology, Renmin University of China; Sandra Graham, Department of Education, University of California, Los Angeles.

This article is based on a doctoral dissertation by the first author submitted to the Graduate School of Education and Information Studies at the University of California, Los Angeles.
} 
(Kawabata \& Crick, 2008), and less feelings of vulnerability at school (Graham, Munniksma, \& Juvonen, 2014).

Despite the growing interest in understanding cross-ethnic friendships, most of the research has focused primarily on White and Black children (see review in Graham, Taylor, \& Ho, 2009). Thus little is known about how the "new immigrants" in America-those accounting for the growing diversity of K-12 schooling, - are shaping the study of cross-ethnic friendships and peer relations more generally. In the present study, we addressed this gap in knowledge by focusing on a largely neglected group in the friendship literature-Asian American adolescents.

Asian Americans constitute the fastest growing group in the United States during the past decade (Hoeffel, Rastogi, Kim, \& Hasan, 2012). By the year 2010, the Asian enrollment in U.S. public schools was over 2.4 million, and projections suggest that the enrollment will be more than 3 million by 2020 (Snyder \& Dillow, 2013). Asian students, on average, also attend more ethnically diverse schools than any other racial/ethnic group (Orfield \& Lee, 2007). Largely ignoring these demographic trends, existing psychological studies on Asian American youth have primarily focused on their academic achievement and mental health adjustment. Asian students are largely portrayed as a model minority because of their academic excellence (Min, 2005). However, they are more likely to suffer from anxiety, depression and lower self-esteem than their White and Black peers (Hsin \& Xie, 2014; Bankston \& Zhou, 2002). A small discrimination literature also indicates that Asian American adolescents experience more peer discrimination than other ethnic minority groups, which is probably because their academic excellence leads to perceived teacher favoritism and peer resentment (Rosenbloom \& Way, 2004; Qin, Way \& Mukherjee, 2008). Given the importance of friends to healthy development during adolescence and the social challenges that may confront Asian American youth because of their academic standing, surprisingly little is known about friendship choices of Asian students in ethnically diverse school contexts. For example, what factors influence the likelihood that Asian students will form cross-ethnic friendships? Are they more likely to befriend Whites (the majority and privileged group in this society) compared to other ethnic minority groups, specifically, Black peers (the traditional minority group) and Latino peers (the largest recent immigrant group)? What is role of school factors in shaping friendship choices? And how do friendships with other ethnic peers influence Asians' thoughts and feelings about the outgroups?

In the current study, we addressed these questions with a very ethnically diverse middle school sample that included a large Asian population residing in schools that varied in ethnic diversity. We examined the determinants and correlates of Asian students' friendships, with a particular focus on cross-ethnic friendships and intergroup attitudes. Studying cross-ethnic friendships and intergroup attitudes of Asian American youth during early adolescence allowed us to examine what is unique about the friendship choices of the fastest growing immigrant group in the U.S. at a developmental period when both ethnicity and peers take on heightened significance. In focusing on relations between cross-ethnic friendships and intergroup attitudes, we offer new insights into one of the most important perceived benefits of crossing ethnic boundaries to form close ties. We do this with a racial/ethnic group that is 
rarely studied in the interracial attitudes literature and, as relative newcomers, does not have a long historical legacy of contact with other ethnic groups in the United States. In reviewing the relevant cross-ethnic friendship research, we highlight some of the methodological limitations in previous research that our study was also designed to address.

\section{Determinants of Cross-ethnic Friendships}

\section{School Level Factors Influencing Cross-ethnic Friendships}

Two central principles identified in the friendship literature are homophily (similarity) and propinquity (availability). Homophily refers to the tendency to form friendships with similar others (McPherson, Smith-Lovin \& Cook, 2001). A robust finding in the interracial friendship literature is that students from all ethnic groups show a strong in-group preference in friend choice (e.g., Hallinan \& Williams, 1989; Hamm, Brown, \& Heck, 2005). Besides ethnicity, similarity in group status could also be an important determinant of interracial friendships (Allport, 1954). Because academic achievement is a powerful indicator of group status in secondary schools (Lee, 2009), we hypothesized that greater school level similarity in achievement between Asians and other ethnic groups would be associated with choosing more friends from that group.

Propinquity refers to the tendency to form friendships with others who are readily available (Mouw \& Entwisle, 2006). Drawing on this principle, a number of studies have examined preference for cross-ethnic friends as a function of the racial and ethnic composition of classrooms and schools (e.g., Hallinan \& Smith 1985; Joyner \& Kao, 2000; Quillian \& Campbell, 2003). This line of research documented that as the proportion of out-group members increased at the classroom or school (other ethnic peers are more available), students were more likely to have cross-ethnic friends (Moody, 2001; Joyner \& Kao, 2000; Quillian \& Campbell, 2003). Thus we hypothesized that Asian students would be more likely to form friendships with White, Black and Latino peers as the numerical representation of those groups increased in their school.

\section{Individual Level Factors Influencing Cross-ethnic Friendships}

We examined three factors measured at the individual level that might influence Asian American students' willingness to form friendships with other-ethnic peers. The first characteristic is student's socioeconomic status (SES). Studies with White and Black adolescents revealed that the greater the disparity in socioeconomic status between African American and White youth in a setting, the less frequently members of these groups embrace cross-ethnic friendships (Miller, 1990). We suspect that SES will also affect the likelihood that Asian students will form friendships with peers from different racial/ethnic groups. In their discussion of immigrant adaptation, Portes and Zhou (1993) proposed that there is no single "core group" with which immigrants merge, and family resources influence which group immigrant children assimilate to. Middle-class Asian-decent youth, in particular, are encouraged by parents to form relationships with White peers as a way to promote assimilation (Lee, 2009). Thus we predicted that Asian students with higher SES would be more likely to befriend Whites. 
A second characteristic pertinent to this sample is generational status. Existing studies on whether Asian students' cross-ethnic friendship patterns may differ across generations offer a mixed picture on this issue. Some research suggests that longer residence in the United States is related to more cross-ethnic friend nominations among Asian adolescents (Hamm et al., 2005), whereas other findings report that generational status matters little (Quillian \& Campbell, 2003). In our research, we measured generational status of Asian students but did not have any specific hypothesis about its effects on friendship choices.

The third individual characteristic examined is Asian subgroup. Asian-American as a panethnic category is now commonly used in the cross-ethnic peer relations literature (e.g., Moody,2001; Quillian \& Campbell, 2003) and in government education statistics (e.g., California Department of Education statistics). The pan-ethnic label aggregates across numerous groups as if they are homogenous and therefore masks the heterogeneity of Asian Americans (Hune, 2002). For example, the position of South Asians as Asian Americans has been a controversial issue in the United States (Shankar \& Srikanth, 1998). Census respondents of South Asian origin (e.g., Indian and Pakistani) have been classified variously as 'Hindu', 'White', 'Other', and 'Asian' (Koshy, 1998). In addition, South Asian Americans often experience subjective "racial ambiguity" and reported feeling apart from other Asians due to differences in physical appearance, languages, cultural and immigrant history (Shankar \& Srikanth, 1998). Given these distinctive features, we speculate that South Asians might have different patterns of friendship choices and attitudes toward other ethnic groups than East Asians and Southeast Asians, although we did not offer specific predictions about within-group differences.

\section{Cross-ethnic Friendships and Intergroup Attitudes}

One reason for psychologists' interest in cross-ethnic friendships lies in the presumed role of cross-ethnic friendships in promoting better intergroup attitudes. In classical intergroupcontact theory, Allport (1954) posits that contact between members of different groups can promote positive attitudes and reduce prejudice as long as the groups have equal status, work cooperatively, and share common goals. In his reformulation of contact theory, Pettigrew (1998) pointed out that cross-ethnic friendships satisfy many of Allport's conditions and are therefore a powerful form of contact. A recent meta-analysis of the friendship-attitude linkage (Davies, Tropp, Aron, Pettigrew, \& Wright, 2011) indicates that cross-ethnic friendships are related to improved intergroup attitudes, although many methodological factors influence the strength of the effect.

One factor affecting the friendship effect is the type of intergroup attitude examined. Intergroup attitudes have been conceptualized as multi-dimensional in the contact literature (Tropp \& Pettigrew, 2005). Specifically, the affective dimension denotes emotional ties with out-group members, such as liking and feelings of intergroup comfort. The cognitive component focuses on stereotypes about the out-group. A widely used measure of cognitive attitudes is trait typicality (e.g., Brown \& Bigler, 2002), which assesses people's beliefs about the extent to which stereotypical traits apply to an out-group (e.g., how many Asians are smart; how many African Americans are mean?). A third but less studied distinct dimension of intergroup attitude is desire for social distance (Bogardus, 1933), which taps 
the behavioral avoidance of another group. Recent meta-analyses (Tropp \& Pettigrew, 2005; Davies et al., 2011) revealed that affective attitudes yielded stronger relations with crossethnic friendships than did cognitive indicators. However, there is almost no research that includes a comprehensive assessment of intergroup attitudes that would allow an explicit comparison of the strength of relations between cross-ethnic friendships and different dimensions of attitudes.

Another key factor affecting the friendship-attitude association is the type of friendship measure. Davies et al. (2011) summarized six categories of friendship assessment that are most commonly found in the intergroup contact literature. Included among the categories were number of cross-ethnic friends, time spent with those friends, and quality indicators like felt closeness and support. Although all types of friendship were associated with intergroup attitudes, these analyses cannot tell us about the unique link between different aspects of friendship and different attitude dimensions. For example, spending time with out-group friends might be particularly effective in reducing desire for social distance from the out-group, just as emotional closeness experienced in a friendship dyad might be particularly influential in promoting more positive feelings toward the out-group. It is therefore important that studies of the relations between cross-ethnic friendships and intergroup attitudes assess both friendship quality and quantity as well as different types of intergroup attitudes that capture affective, cognitive, and behavioral components.

\section{The Current Study}

With a large multiethnic sample that included close to $8006^{\text {th }}$ grade Asian American students recruited from middle schools that varied in ethnic diversity, we examined Asian students' cross-ethnic friendships and their consequences for intergroup attitudes. We selected $6^{\text {th }}$ graders because friendships take on added significance in early adolescence (Brechwald \& Prinstein, 2011) and increased social-cognitive maturity along with more social exposure during the transition to middle school make ethnicity more salient to young adolescents (Umaña-Taylor et al., 2014). In addition, social identities, including those about race, that highlight boundaries between in-group and out-groups become increasingly important during adolescence (Knifsend \& Juvonen, 2014; Sani \& Bennett, 2004). Using peer nominations, we studied Asian students' friendships with grade-mates who were White, Black, and Latino. We also examined how these friendships were related to intergroup attitudes. In contrast to most of the contact literature, we included multiple measures of friendship quality and we assessed affective, cognitive, and behavioral dimensions of intergroup attitudes. Thus the specific link between different aspects of friendship and different dimensions of attitudes could be investigated.

Two sets of hypotheses about the predictors and consequences of Asians' cross-ethnic friendships were tested. Hypotheses about predictors were derived from homophily (similarity) and propinquity (availability) principles First, based on homophily, we predicted that Asian students would show an in-group preference when choosing friends. In addition, since Asian American students are characterized by relatively high academic achievement, we hypothesized that similarity in achievement would predict Asians' friendships with cross-ethnic peers. Based on propinquity, we predicted that as both school diversity and the 
availability of different ethnic groups increased, Asian students would be more likely to form friendships with members of those groups. Turning to consequences and consistent with contact theory, we predicted that cross-ethnic friendships would be related to better intergroup attitudes, although we did not have specific hypothesis about the unique linkages between different aspects of friendships and various dimensions of attitudes. Finally, in exploratory analyses, we examined possible differences in friendships and attitudes among different Asian sub-groups. We suspected that South Asians' cross-ethnic close ties might differ from those of East Asians and South East Asians in our sample.

\section{Method}

\section{Sample and Participant Selection}

The data for this study come from the UCLA Middle School Diversity Project (MSDP), an ongoing longitudinal study that examines social and academic outcomes in a large sample of middle school students attending public schools throughout California. In the fall of 2009, $6^{\text {th }}$ grade students from six middle schools in the Los Angeles area were recruited to participate as Cohort 1 . In the fall of $2010,6^{\text {th }}$ graders from an additional 14 middle schools (8 schools in Los Angeles and 6 schools in Northern California) joined the study as Cohort

2. Because this project focuses on the relations between school ethnic diversity and students' social and academic outcomes, schools recruited for participation varied in their ethnic composition. For example, some schools have one dominant ethnic group (e.g., Asian) and several smaller minority groups, with the particular ethnic majority group varying from school to school. Other schools have two majority ethnic groups about the same size (e.g., Asian-White, Asian-Latino). Still other schools have several equally represented groups with no numerical majority group. To reduce confounds of ethnic diversity with socioeconomic status (SES), schools at the extremes of the SES continuum were avoided; only schools within a $20-80 \%$ range of free or reduced price lunch eligibility were included. Recruitment rates ranged from 69 to $94 \%(M=81 \%)$, and participation rates ranged from 74 to $94 \%(M=83 \%)$ across the 20 participating schools.

As part of the research protocol, students were asked to select their ethnicity from the following 13 options: American Indian, Black/African-American, Black/other country of origin, Latino/other country of origin, Mexican/Mexican-American, Middle Eastern, Pacific Islander (e.g., Samoan, Filipino), East Asian (e.g., Chinese, Korean, Japanese), Southeast Asian (e.g., Vietnamese, Cambodian, Thai, Laotian), South Asian (e.g., Indian, Pakistani), White/Caucasian, Multiethnic/Biracial, and Other. For this study, we combined some ethnic categories to capture the major ethnic groups: Black/African-American and Black/other country of origin were combined and labeled as Black; Mexican/Mexican-American and Latino/other country of origin were combined and labeled as Latino; and East Asian, Southeast Asian, and South Asian represented the Asian sample for the analyses. Since we relied on statistics from California Department of Education (CDE) for school level variables, we adhered to the $\mathrm{CDE}$ definition of Asian which treats Pacific Islanders as a separate racial category. Pacific islanders $(N=133)$ were therefore excluded from our Asian sample. Finally, one Black-Latino school with no Asian students at $6^{\text {th }}$ grade was excluded, resulting in a final sample of 4,923 students from 19 schools ( $48 \%$ boys, $52 \%$ girls). The 
ethnic breakdown of the sample was 17\% Asian, 17\% White, 10\% Black, 32\% Latino, 18\% multiethnic/biracial, and $6 \%$ who self-identified as other ethnic groups.

Asian sub-sample-Of the 762 Asian students, $60 \%$ were East Asian $(N=456), 26 \%$ were Southeast Asian $(N=194), 11 \%$ were South Asian $(N=87)$, and another 25 were EastSoutheast Asian biracial. The East Asians were primarily Chinese and Korean, the majority of Southeast Asians were Vietnamese, and most South Asian students were Indian and Pakistani. Almost all of the Asian students were recent immigrants or children of immigrants (30\% $1^{\text {st }}$ generation, $64 \% 2^{\text {nd }}$ generation, and $6 \% 3^{\text {rd }}$-plus generation).

Procedure

Students with both written parental consent and student assent completed confidential surveys during the spring semesters of 6th grade in a nonacademic class. Students were instructed to answer survey questions on their own as a trained research assistant read the survey items aloud. A second research assistant circulated around the classroom to help students as needed. Students were given an honorarium of $\$ 5$ for completing the questionnaire.

\section{Measures}

Friendship-Students were asked to list the names of their good friends in their grade at their school. They could list as many names as they wanted. The ethnicity of nominated friends who were in the sample was determined by their self-report ethnic identification.

Since our major interest was how individual and school factors influenced Asian students' choice of friends, we focused on Asian students' friendship nominations, regardless of whether or not the friendship was reciprocated by the nominee (see Joyner \& Kao, 2000 for another example based on Add Health data). In addition, self-report of friendship is commonly used in the intergroup friendship-attitude literature (e.g., Binder et al., 2009; Levin, van Laar, \& Sidaniu, 2003; Pettigrew, 1997).

Friendship quality: For each nominated friend, students were asked to rate the quality of that friendship. One question captures spending time together outside of school ("We go to each other's houses after school or on weekend"). Three questions asked about the degree of emotional support provided by the friend (e.g., "This friend helps me feel better when I'm upset"). Each item was rated on a 3-point frequency scale $(1=$ No/Hardly Ever, $2=$ Sometimes, and $3=$ Yes/Almost all the Time $)(\alpha=.77)$.

Intergroup attitudes-Three aspects of intergroup attitudes were assessed.

Affective attitudes: The affective dimension was assessed by asking students to rate how they feel about (i.e., like, trust, respect, comfortable being around...) kids from each of the four major ethnic groups: Asian, White, Black, and Latino. An example item is, "I like kids who are Latino" ( $1=$ no way, $5=$ for sure yes). Alpha coefficients were $.87, .88$, and .88 for feelings toward Whites, Blacks and Latinos respectively. 
Cognitive evaluations of groups: The cognitive measure of intergroup attitudes examines perceptions of the typicality of particular traits in specific groups (e.g., Brown \& Bigler, 2002). Participants were presented with four positive traits (kind, honest, smart, friendly) and four negative traits (selfish, mean, bossy, lazy). They were asked to determine how many people from each of the major ethnic groups possess that trait (e.g., "How many Latino kids are ?") Response options created a 5-point scale (1= hardly any, 5=almost all). Alpha coefficients ranged from .82 to .87 for positive and negative trait evaluations of each ethnic group.

Desire for social distance: Social distance captures the behavioral intention aspect of intergroup attitudes. Adapted from Bogardus' (1933) original social distance scale, participants were asked to rate the likelihood that they would engage in four activities (i.e., eat lunch together, visit each others' homes, dance together at a school party, sit together on a school bus) with peers from different ethnic groups. An example item is "Would you want to eat lunch together with kids who are Latino (White etc.)". The 5-point response scale ranged from $1=$ for sure yes to $5=$ no way, with higher score indicating more desired social distance (as $=.86, .87$, and .88 for desired social distance toward Whites, Blacks, and Latinos respectively).

\section{School Characteristics}

School availability: Proportions of each ethnic group in the student body at school were used as indicators of school availability for friendship choices. Information about school ethnic composition was retrieved from the website of CDE. Since our study focused on $6^{\text {th }}$ graders' friend nominations within the same grade, we used $6^{\text {th }}$ grade ethnic composition for the analyses.

Ethnic diversity: $6^{\text {th }}$ grade level ethnic diversity was measured by Simpson's (1949) index.

$$
\mathrm{D}=1-\sum_{\mathrm{i}=1}^{\mathrm{g}} \mathrm{p}_{\mathrm{i}}^{2}
$$

In the above formula, $p_{i}$ is the proportion of students who are in ethnic group $i$. This proportion is squared $\left(\mathrm{p}_{\mathrm{i}}^{2}\right)$, summed across $g$ groups, and then subtracted from 1. Ds give the probability that any two students randomly selected from a school will be from different ethnic groups. Values can range from 0 to approximately 1 , where higher values indicate greater diversity . Simpson's index of participating schools ranged from .48 to .75 ( $M=.63$, $S D=.08)$.

Group disparity in achievement: The mean math score from California Standards Tests (CST) was used as an indicator of academic achievement for each ethnic group. Disparity scores between Asian and the other ethnic groups were calculated for each school. For example, at one school, Asian students' mean CST math score was 426, and Latino students' mean CST math score was 358. The disparity score between Asians and Latinos at this school was 426-358=68. 


\section{Individual level variables}

Generational status: Students' generational status was determined by a question in which students indicated whether they, and their parents were born in the United States. Firstgeneration students are those born outside the United States. Second-generation students are born in the United States, and at least one of their parents was foreign born. The third-plus generation consists of native-born students whose parents were also born in the United States.

SES: Student SES was indicated by parent education level reported by participants' parents. The response options ranged from 1 (elementary/junior high school) to 6(graduate degree). Mean SES of the Asian sample was $4.36(S D=1.53)$.

Academic grade-point average (GPA): Students' transcripts from Spring semester at $6^{\text {th }}$ grade were used to calculate GPA using 5-point scales, with A, B, C, D and F worth 4, 3, 2, 1 and 0 points respectively. We included students' grades for four major academic courses (i.e., Math, science, English, and social studies) to calculate their academic GPA. In our sample, Asian students had the highest GPA among the four major ethnic groups (Asians: $M=3.38, S D=.71$; Whites: $M=3.23, S D=.79$; Latinos: $M=2.61, S D=.89$; and Blacks: $M=2.53$, $S D=.91)$. Asians' GPA was significantly higher than that of the other three ethnic groups $(p s<.01)$.

\section{Results}

\section{Analytic Plan}

The analyses proceeded in three steps. First, school-by-school preliminary analyses were carried out to explore Asian students' friendship nomination patterns when school availability was accounted for. Next, multilevel logistic regression analyses were conducted to examine individual and school level factors predicting Asian students' cross-ethnic friendships. Third, we performed multilevel regression analyses to explore the friendship effect on the different dimensions of intergroup attitudes. In this set of analyses, we first examined the effect of having an out-group friend on affective, behavioral and cognitive attitudes; then with a trimmed sample of students who had at least one out-group friend, we examined the effect of each friendship quality measure on different dimensions of attitudes. To explore characteristics associated with particular ethnic composition of friend dyads, we conducted separate analyses for Asian-White, Asian-Latino and Asian-Black friendships.

\section{Asian Students' Friendship Nomination Patterns}

The 762 Asian students in the sample made a total of 2521 friend nominations. Since $91 \%$ of these nominations $(N=2293)$ were same gender friends, our analyses only focused on samegender friendships. Of these same-gender friend nominations, 55\% were Asian (i.e., sameethnic friends, $N=1256), 10 \%$ were White $(N=231), 12 \%$ were Latino $(N=276), 4 \%$ were Black $(N=90), 13 \%$ were multiethnic, and $6 \%$ were peers who self-identified as other ethnic groups. Since the focus of our study was Asian students' relations with peers from the three major ethnic groups, multiethnic and other ethnic students were excluded from further analyses. 
About 25\% of the Asian participants reported having at least one White or Latino friend, but only $10 \%$ had at least one Black friend. South Asian students were more likely to report having at least one cross-ethnic friend than were students from the other two Asian subgroups (White: $X^{2}(2, N=762)=23.78, p<.001$; Black: $X^{2}(2, N=762)=29.76, p<.001$; and Latino: $\left.X^{2}(2, N=762)=7.53, p<.05\right)$. The percentage of Asian students who had crossethnic friends did not differ by gender or generational status.

School-by-school analysis-If Asian students' friend choices were based on availability of each ethnic group at their school, then the share of friends from each group should mirror the ethnic composition of the school. For each ethnic group within each school, we used a procedure reported by Hamm et al. (2005), that yielded a $z$-score as a test of whether the observed friend nomination patterns by Asian students were equivalent to expected nomination patterns based on school ethnic composition. The formula for the $z$ score is:

$$
z=\frac{p-\pi}{\sqrt{\pi(1-\pi) / n}}
$$

where $p$ is the total number of friend nominations of members of the target group divided by the total number of nominations; $\pi$ is the total number of students in the target group divided by the total number of students in the school; and $n$ is the total number of nominations. For example, at one school Asian students made up $10.2 \%$ of the student body, and they made 51 friend nominations, of which $41.2 \%$ were Asian. In that case,

$z=\frac{41.2 \%-10.2 \%}{\sqrt{10.2 \% *(1-10.2 \%) / 51}}=7.34, p<.001$. Thus same ethnic peers were over-nominated as friends by Asian students. A negative $z$ score would indicate under nomination of peers from a particular ethnic group when school availability was accounted for. Results indicated that Asian students over-nominated same-ethnic friends in most schools (z-scores: 10 16.04). Black and Latino students were significantly under-nominated by Asian students at 12 and 11 of the 19 schools respectively, and Black and Latino students were never significantly over-nominated ( $z$-scores: $-4.58 \sim 1.40$, and $-6.08 \sim 0.71$ for Latino and Black friendships, respectively). At two schools where Asians were a small minority (less than $8 \%$ of the student body), Asian students over-nominated Whites as their friends ( $z$-scores $=2.00$ and 1.99 respectively).

\section{Individual and school predictors of cross-ethnic friend nominations-To} explore student and school factors influencing Asian students' cross-ethnic friend nominations, we carried out a set of multilevel logistic regression analyses. At level 1 (student level), the log-odds of having at least one cross-ethnic friend was regressed on student's gender, generational status, region of Asia, parent education level, and student GPA. Two dichotomous variables—gender and generational status-were entered as $0=$ male, and $0=$ first generation; South Asian was used as the reference group for the region analysis. We also included student's total number of friends as a level 1 predictor, which was an indicator of the person's general tendency to make friends with peers. All level 1 
predictors were group-mean centered, thus the intercept of level $1\left(\beta_{0 j}\right)$ was the unadjusted school mean log-odds of having at least one cross-ethnic friend.

We first established a base model (Model 1 in Tables 1 and 2) with no school level predictors. Next, we added school level predictors (i.e., \% out-group, \% Asian, school diversity, and discrepancy in achievement) one by one to the base model (Models 2-5), allowing the intercept to vary across schools. Separate analyses were carried out for nominations of White and Latino friends (Appendices S1 and S2 show the equations for each model). Due to the small number of Black friends nominated by Asian students (there were only 90 Asian-Black nominations) and at 13 schools the number of Asian students who had at least one Black friend was less than 5, multilevel modeling was not appropriate to explore Asian-Black friendships.

Asian-White friendships: As shown in Model 1 in Table 1, after controlling for the total number of friends a student had, South Asians were more likely than East Asians to have a friendship with a White grade-mate. None of the other student level predictors was significant. In Model 2, percentage of White students was a significant school level predictor. The likelihood that Asian students nominated as least one White friend was higher in schools with a larger share of Whites in the student body. In Model 3, adding percent Asian showed that Asian students were significantly less likely to nominate a White friend as the size of their own group increased. A significant diversity effect was found in Model 4. After controlling for the availability of Whites and Asians, Asian students were more likely to befriend White grade-mates in schools with more ethnic diversity. The discrepancy in achievement between Whites and Asians (Model 5) was not a significant school level predictor.

Asian-Latino friendships: GPA was a significant student level predictor in each model (see Table 2). Asian students with a lower GPA were more likely to nominate at least one Latino friend. As shown in Models 2 and 3, both percent Latino and percent Asian at school were significant school level predictors. Asian students were more likely to have a Latino friend when there was a larger share of Latinos and a smaller percentage of Asians at their school. In Model 4, ethnic diversity was not a significant school level predictor. In Model 5, the discrepancy in achievement between Asians and Latinos was a significant level 2 predictor. The likelihood that Asian students nominated at least one Latino friend was higher in schools where Asian students' academic achievement was more similar to that of their Latino peers.

Asian-Black friendships: As an alternative to multilevel modeling, we explored achievement differences between Black students who were nominated by Asians as friends compared to Black non-friends. Academic achievement was indicated by $6^{\text {th }}$ grade spring semester GPA. Black students' GPA was standardized within school within ethnic group; thus the standardized scores indicated students' relative standing on academic achievement among same ethnic peers in their school. Among Black students who were nominated by Asians as their friends, $61 \%$ had a GPA above their group mean (i.e., $z$-GPA>0), whereas among Black students not nominated by Asians, only $38.8 \%$ had an above average GPA $\left(\chi^{2}\right.$ 
(1) $=4.74, p<.05$ ). This result suggested that Asian students were more likely to befriend higher-achieving Black peers.

To summarize, results of friendship pattern analyses revealed that Asian students showed a strong in-group preference in choosing friends. South Asians were more likely to seek crossethnic friends than the other two subgroups. When choosing cross-ethnic friends and availability was accounted for, Asian students tended to over-nominate Whites when the number of own-group peers was very small, whereas they more often under-nominated Black and Latino peers. School ethnic diversity promoted more Asian-White friendships whereas similarity in academic achievement promoted more Asian-Latino and Asian-Black friendships.

\section{Cross-ethnic Friendships and Intergroup Attitudes}

Existence of an out-group friend-As shown in the left panel of Figure 1, compared to those who did not have any White friends, Asian students who had at least one White friend showed significantly better attitudes toward Whites on all attitude measures (i.e., more positive feelings, $t(485)=3.97$; less desire for social distance, $t(724)=-5.00$; more positive, $t(717)=3.10$; and less negative cognitive evaluations, $t(682)=-2.74$, all $p s<.01)$, and the effect sizes were stronger for behavioral ( $r=.20)$ and affective attitudes $(r=.18)$ compared to cognitive evaluations ( $r s=.12$ and .10 for positive and negative traits respectively). A similar friendship effect on attitudes was also found for Asian-Latino friendships. However, having a Black friend was significantly related only to less behavioral avoidance toward Blacks $(t(762)=-3.58, p<.001, r=.13)$. Black friendships were marginally related to more positive affective ties $(t(482)=1.94, p=.052, r=.09)$, but not to improved cognitive evaluations (and the effect sizes for both positive and negative trait evaluation were very small, $r s<.05)$.

Next, multilevel analysis (Raudenbush \& Bryk, 2002) was performed to examine the friendship effect on the different dimensions of intergroup attitudes toward Whites and Latinos. As shown in the equation below, at the student level (level 1), attitude score was regressed on demographic variables (gender, generation, parent education, and region of Asia) and existence of a cross-ethnic friendship. All level 1 predictors were group-mean centered. Thus $\beta_{0 \mathrm{j}}$ represented the unadjusted school mean attitude score. Because preliminary analyses showed little variation in the slope of the friendship effect across schools, for these analyses only the intercept varied randomly at level 2.

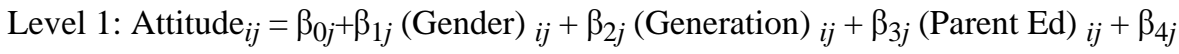

$$
\begin{aligned}
& \left.\left.(\text { SouthestAsian })_{i j}+\beta_{5 j} \text { (EastAsian) }\right)_{i j}+\beta_{6 j} \text { (Friend }\right)_{i j}+e_{i j} \\
& \text { Level 2: } \beta_{0 j}=\gamma_{00}+u_{0 j} \text {, } \\
& \beta_{\mathrm{p} j}=\gamma_{\mathrm{p} 0}, \text { for } p>0 \text {. }
\end{aligned}
$$

As shown in Table 3, after controlling for demographic variables, having an out-group friend was associated with more positive feelings, less behavioral avoidance, more positive trait evaluations, and less negative trait evaluations toward the out-group as a whole. This was true for both Asian-White and Asian-Latino friendships. Compared to boys, girls showed significantly less desire for social distance toward Whites and Latinos, and girls also 
reported significantly more positive feelings toward Latinos. No generational difference was found on any attitude measure. Significant regional differences indicated that compared to East Asian students, South Asians showed better attitudes toward both Latinos and Whites on affective, behavioral and positive trait evaluations. In addition, South Asians had significantly better affective and positive trait evaluations toward Latinos and Whites than Southeast Asians. The three Asian subgroups did not differ on negative trait evaluations of Whites or Latinos. We also rotated the Asian reference group, and found no significant differences between East and Southeast Asians.

Friendship qualities-Next, similar procedures were carried out to examine the effect of each friendship quality measure (i.e., spending time together and emotional support) with the trimmed sample of students who had White or Latino friend(s). Different aspects of friendship quality revealed distinctive relations with particular dimensions of intergroup attitudes. As shown in Table 4, for both Asian-White and Asian-Latino friendships, spending time together with out-group friend(s) was a significant predictor of less behavioral avoidance toward the out-group but not affective attitudes or trait evaluations. As shown in Table 5, for Asian-White friendships, emotional support was a significant predictor of less behavioral avoidance toward Whites. For Asian-Latino friendships, emotional support significantly predicted every dimension of attitudes.

\section{Discussion}

Friendships are critical for healthy development of children and adolescents. Because the school age population is becoming ethnically and racially diverse at a more rapid pace than at any other age, the study of cross-ethnic friendships in schools will become even more important over time. The current study extended existing literature by examining the predictors of cross-ethnic friendships and their consequences for intergroup attitudes among Asian American adolescents. Thus we examined a normative developmental process-the influence of friendships on social adaptation-in a population largely overlooked in friendship research. We emphasize two patterns to the findings that make original contributions to the cross-ethnic friendship literature.

\section{Asian Students' Friendships with Whites, Latinos, and Blacks}

First, this study demonstrated that Asian American students had distinctive relations with peers from different ethnic groups. Consistent with the homophily hypothesis, Asian students disproportionately favored same-ethnicity friends. In schools with a small number of same-ethnicity peers, Asian students over-nominated Whites as their friends when school availability was accounted for. However, they never over-nominated other ethnic minority peers as their friends; more often than not, Latinos and Blacks were significantly undernominated by Asian students. This pattern is consistent with previous research documenting that students from all ethnic groups showed strong own-group preference when choosing friends, and that Asian students' preferred out-group friendships were with Whites (Kao \& Joyner,2004; Quillian \& Campbell, 2003). After controlling for group size, higher level of school ethnic diversity was related to more Asian-White friendships, but not to more AsianLatino friendships. Asian-Black friendships were particularly rare in our sample, in part due 
to availability. There were few schools in our sample with substantial numbers of Asian and Black students (reflecting racial segregation throughout the state of California). In schools with a large number of Black students (Black-majority and Black-Latino schools), there were few to no Asians. Lack of contact could be one key reason for the rarity of AsianBlack friendships.

One variable that showed a significant effect on friendship nominations was academic achievement. In general, Asian students have higher academic achievement than Blacks and Latinos (e.g., Bankston \& Zhou, 2002; Hsin \& Xie, 2014), an achievement disparity that was documented in our sample. When Asian students chose friends from other ethnic minority groups, they tended to befriend those who had similar academic performance. Lower Asian GPA was associated with higher likelihood of having at least one Latino friend; and when Asian students had friendships with Blacks, they befriended those who were relatively high-achieving compared to other Black students in the school. Similarity in academic achievement may lead to more contact opportunities between Asians and other ethnic minority students in achievement-grouped classes, which then fosters formation of cross-ethnic friendships.

In addition to individual level GPA, relative achievement status at the group level was also a significant predictor of Asian students' friendships with Latinos. Asian students were more likely to have a Latino friend when the discrepancy in average academic achievement between Asians and Latinos at the school was smaller. This finding is consistent with previous research carried out with Black and White youth (Hallinan \& Teixeira, 1987). In classrooms where the academic-status hierarchy was not salient, White students were more likely to cross the racial boundary to befriend Blacks. From the perspective of contact theory (Allport, 1954), similarity in group level achievement is a sign of "equal status" between groups, which is an optimal condition for intergroup contact. Thus a classroom climate that focuses on curriculum mastery and cooperation and deemphasizes achievement hierarchy based on grades and test scores may serve to promote Asian-Black and Asian-Latino friendships.

\section{Cross-ethnic Friendships and Intergroup Attitudes}

Aligned with contact theory, cross-ethnic friendships were related to improved intergroup attitudes and this friendship effect on intergroup attitudes differed by target out-group. Having a White or Latino friend was related to better feelings, more behavioral closeness, and better cognitive evaluations of the out-group. However, having a Black friend did not diminish negative stereotypes about Blacks; nor did it significantly improve feelings toward that group. And Asian-Black friendships yielded smaller effect sizes compared to that of Asian-White and Asian-Latino friendships. These findings are consistent with a developmental intergroup perspective (Killen, Mulvey, \& Hitti, 2013), which stresses the importance of status differences between groups, and the historical, societal, and cultural forces that shape youth's peer contact. Even though they are relative new comers (over 90 percent were first or second generation), Asian students' pattern of cross-ethnic friendships and intergroup attitudes in our sample mirrors the racial hierarchy in U.S. society. When Asian students cross ethnic boundaries to form friendships, Whites (the societal privileged 
group) were their most desired friends; even when they form friendships with a lower status group, especially Blacks, their attitudes about the negatively stereotyped group were least likely to change. Our results underscore the importance of attending to the specific ethnic composition of the friend dyads when studying cross-ethnic friendships and intergroup attitudes, which has been largely ignored in previous research.

Our study is also one of the first to include multiple measures of friendships (both quantity and quality) and intergroup attitudes (see Binder et al., 2009 for another example). We found unique linkages between particular aspects of friendships and different dimensions of attitudes. Spending time with a White or Latino friend was uniquely related to less behavioral avoidance of the out-group. Spending time with a cross-ethnic friend provides opportunity for repeated contact with the out-group member, and a cross-ethnic friend might also serve as a broker who could introduce the student to more out-group members. Quality time with an out-group friend could also help reduce intergroup anxiety (Stephan \& Stephan, 1985; Paolini, Hewstone, Carrins, \& Voci, 2004), which results in less behavioral avoidance toward the entire out-group.

Emotional support from cross-ethnic friendships showed even stronger effects on intergroup attitudes. For Asian-White friendships, emotional support was linked to significantly less behavioral avoidance toward Whites. For Asian-Latino friendships, emotional support was significantly related to all dimensions of attitudes toward Latinos. This finding is consistent with Pettigrew's (1998) argument about the critical role of emotions in intergroup contact, and it highlights the importance of affective ties in changing attitudes toward out-groups. Emotional support from the friendship reflects partner responsiveness to the student's psychological need, which is important in enhancing intimacy levels in close friendships (Shelton, Trail, West, \& Bergsieker, 2010). Greater feelings of intimacy with individual outgroup members then result in less prejudice toward the out-group as a whole.

One of our most novel findings was that relations with out-group peers differed across Asian sub-groups. To our knowledge, no study has previously explored subgroup differences in Asian adolescents' friendship preferences and attitudes. Given the increasing diversity of Asian immigrants in the U.S., it is important to acknowledge within group variations under the pan-ethnic Asian umbrella. We distinguished South-, East-, and Southeast Asians, documenting that South Asian students reported more cross-ethnic friendships and better intergroup attitudes than did their East Asian and Southeast Asian peers. One possible explanation for this pattern could be relatively less cultural distance (Babiker, Cox, \& Miller, 1980) between South Asian and Western countries due to the long history of colonization on the Indian subcontinent. Consistent with this cultural distance explanation, one recent study documented that South Asian immigrants in the U.S. reported less acculturative stress than did East and Southeast Asians (Tummala-Narra, Alegria \& Chen, 2012). The literature on immigration and acculturation suggests that larger cultural distance may trigger more negative intergroup attitudes (Berry, 1997), which might be one reason why East and Southeast Asians reported more negative intergroup relations compared to South Asians. We acknowledge that our interpretation is speculative since we did not measure acculturation or cultural distance. Moreover, the Asian American population is heterogeneous along multiple dimensions and we only distinguished them by geographic 
region. Additional research with larger samples, measures of acculturation, and more dimensions of difference is needed to further our understanding of the variation in intergroup relations among different Asian sub-groups. Our study is a first step in that direction.

\section{Limitations of the Research}

Although we believe the current study makes significant contributions to the cross-ethnic friendship literature, we acknowledge its limitations. One limitation involves the directionality issue between friendships and attitudes. Since the study is cross-sectional, we need to be cautious in making causal inferences about the linkages between cross-ethnic friendships and intergroup attitudes. It could be that Asian students who enter middle school with positive intergroup attitudes are more likely to form cross-ethnic friendships (selection effects) to the same degree that cross-ethnic friendships promote improved attitudes (socialization effects). We adopted the friendships-to-attitude change perspective of intergroup contact theory. Longitudinal research employing methods to detect selection versus socialization effects is needed. Studies of bidirectional relations over time between cross-ethnic friendships and intergroup attitudes are essential to understand developmental process. Yet our concurrent findings also have developmental significance. Documenting that friendship quantity and quality both matter for intergroup attitudes, that the strength of relations varies depending on who the target group is, and that some attitudes are more amenable to change than others are valuable first steps toward understanding developmental process that lay the foundation for longitudinal research.

Another limitation of our study relates to generalizability. We focused on $6^{\text {th }}$ grade students, because early adolescence is a time when the peer group becomes more important, race becomes more salient, and social identities along with in-group and out-group distinctions take on heightened significance (Rutland, Abrams, \& Levy, 2007). We also studied the first year of middle school because of the opportunities to form new friendships at the time of a school transition. However, studies with both younger children and older adolescents are needed to fully capture the developmental process of Asian American students' relations with other-ethnic peers. For example, given similar availability (i.e., ethnic composition) in elementary school as in middle school, are younger students more (or less) likely to take up the opportunity to form cross-ethnic friendships? Do Asian students have more segregated friendships and deteriorated intergroup attitudes in high school when math and science tracking become more common? A more nuanced developmental analysis of cross-ethnic peer relations is a goal for future research.

\section{Implications for Intervention}

Consistent with a previous meta-analysis (Tropp \& Pettigrew, 2005), our results showed that cognitive attitudes, especially stereotypes about Blacks shifted very little even in the presence of cross-ethnic friendships. Because stereotypes are culturally shared beliefs and they operate unconsciously as well as consciously (Fiske, 1998; Devine, 1989), they can be remarkably resistant to change. On the more positive side, we documented that the behavioral component of intergroup attitudes was most amenable to the influence of a crossethnic friendship. It is plausible that friendship with an out-group member first promotes 
behavioral closeness toward the out-group, which in turn leads to better feelings and improved cognitive evaluation of the out-group. A task for future research is to investigate a temporal sequence of the form: cross-ethnic friendships $\rightarrow$ behavioral closeness $\rightarrow$ affective change $\rightarrow$ cognitive change. No tests of such motivational sequences exist in the friendshipattitude literature.

What might this hypothesized sequence tell us about programs to change intergroup attitudes? Existing prejudice reduction programs tend to be cognitively-oriented. They focus on changing stereotypes about different ethnic groups directly by increasing knowledge of the out-group (see review in Hill \& Augoustin, 2001). Our results suggest that intergroup attitude interventions might be more successful if they start by promoting behavioral closeness between members of different groups as the route to affective and cognitive change. Creating a school environment that fosters the development of cross-ethnic friendships, which easily translate into behavioral closeness between members of different ethnic groups may be an important first step to set in motion the process of intergroup attitude change.

\section{Supplementary Material}

Refer to Web version on PubMed Central for supplementary material.

\section{Acknowledgments}

This research was supported by grants from the National Institute of Child Health and Human Development (5R01HD059882) and the National Science Foundation to Sandra Graham. The first author would like to thank Jaana Juvonen, Rashmita Mistry, and Connie Kasari, members of her dissertation committee, and Leslie Echols for their helpful suggestions.

\section{References}

Allport, G. The nature of prejudice. Garden City, N.Y: Doubleday Anchor; 1954.

Babiker IE, Cox JL, Mc Miller PG. The measurement of cultural distance and its relationship to medical consultations, symptomatology and examination performance of overseas students at Edinburgh University. Social Psychiatry. 1980; 15:109-116.10.1007/BF00578141

Bangston V, Zhou M. Being well vs. doing well: Self-esteem and school performance among immigrant and nonimmigrant racial and ethnic groups. International Migration Review. 2002; 36:389-415.10.1111/j.1747-7379.2002.tb00086.x

Berry JW. Immigration, acculturation and adaptation. Applied Psychology. 1997; 46:5-68.10.1111/j. 1464-0597.1997.tb01087.x

Binder J, Zagefka H, Brown R, Funke F, Kessler T, Mummendey A. Does contact reduce prejudice or does prejudice reduce contact? A longitudinal test of the contact hypothesis among majority and minority groups in three European countries. Journal of Personality and Soical Psychology. 2009; 96:843-856.10.1037/a0013470

Bogardus ES. A social distance scale. Sociology and Social Research. 1933; 17:265-271.

Brechwald WA, Prinstein MJ. Beyond homophily: A decade of advances in understanding peer influence processes. Journal of Research on Adolescence. 2011; 21:166-179.10.1111/j. 1532-7795.2010.00721.x [PubMed: 23730122]

Brown C, Bigler R. Effects of minority status in the classroom on children's intergroup attitudes. Journal of Experimental Child Psychology. 2002; 83:77-110.10.1016/S0022-0965(02)00123-6 [PubMed: 12408957] 
Davies K, Tropp LR, Aron A, Pettigrew TF, Wright SC. Cross-group friendships and intergroup attitudes: A meta-analytic review. Personality and Social Psychology Review. 2011; 15:332351.10.1177/1088868311411103 [PubMed: 21844287]

Devine PG. Stereotypes and prejudice: Their automatic and controlled components. Journal of Personality and Social Psychology. 1989; 56:5-18.10.1037/0022-3514.56.1.5

Fiske, ST. Stereotyping, prejudice, and discrimination. In: Gilbert, DT.; Fiske, ST.; Lindzey, G., editors. Handbook of social psychology. New York: McGraw-Hill; 1998. p. 357-411.

Fry, R. The Changing Racial and Ethnic Composition of US Public Schools. Pew Hispanic Center; 2007.

Graham S, Munniksma A, Juvonen J. Psychosocial benefits of cross-ethnic friendships in urban middle schools. Child Development. 2014; 85:469-483.10.1111/cdev.12159 [PubMed: 24063663]

Graham, S.; Taylor, AZ.; Ho, A. Race and ethnicity in peer relations research. In: Rubin, KH.; Bukowski, WM.; Laursen, BP., editors. Handbook of peer interactions, relationships, and groups. New York, NY: The Guilford Press; 2009. p. 394-413.

Hallinan M, Smith S. The effects of classroom racial composition on students' interracial friendliness. Social Psychology Quarterly. 1985; 48:3-16.10.2307/3033777

Hallinan M, Teixeira R. Opportunities and constraints: Black-white differences in the formantion of interraical friendships. Child development. 1987; 58:1358-1372.10.2307/1130627 [PubMed: 3665651]

Hallinan M, Williams R. Interracial friendship choices in secondary schools. American Sociological Review. 1989; 54:67-78.10.2307/2095662

Hamm J, Brown B, Heck D. Bridging the ethnic divide: Students and school characteristics in African American, Asian-descent, Latino, and White adolescents' cross- ethnic friend nominations. Journal of Research on Adolescence. 2005; 15:21-46.10.1111/j.1532-7795.2005.00085.x

Hartup WW, Stevens N. Friendships and adaptation across the life span. Current directions in psychological science. 1999; 8:76-79.10.1111/1467-8721.00018

Hill ME, Augoustinos M. Stereotype change and prejudice reduction: Short- and Long-term evaluation of a cross-cultural awareness programme. Journal of Community \& Applied Social Psychology. 2001; 11:243-263.10.1002/casp.629

Hoeffel, EM.; Rastogi, S.; Kim, MO.; Hasan, S. The Asian Population: 2010. US Department of Commerce, Economics and Statistics Administration, US Census Bureau; 2012.

Hsin A, Xie Y. Explaining Asian Americans' academic advantage over Whites. Proceedings of the National Academy of Sciences. 2014; 20140640210.1073/pnas.1406402111

Hune S. Demographics and diversity of Asian American college students. New Directions for Student Services. 2002; 2002:11-20.10.1002/ss.35

Hunter L, Elias MJ. Interracial friendships, multicultural sensitivity, and social competence: How are they related? Journal of Applied Developmental Psychology. 1999; 20:551-573.10.1016/ S0193-3973(99)00028-3

Joyner K, Kao G. School racial composition and adolescent racial homophily. Social Science Quarterly. 2000; 81:810-825.

Kao G, Joyner K. Do race and ethnicity matter among friends? Activities among interracial, interethnic, and intraethnic adolescent friends. The Sociological Quarterly. 2004; 45:557573.10.1111/j.1533-8525.2004.tb02303.x

Kawabata Y, Crick NR. The role of cross-racial/ethnic friendships in social adjustment. Developmental Psychology. 2008; 44:1177.10.1037/0012-1649.44.4.1177 [PubMed: 18605843]

Killen M, Mulvey KL, Hitti A. Social exclusion in childhood: A developmental intergroup perspective. Child development. 2013; 84:772-790.10.1111/cdev.12012 [PubMed: 23170901]

Knifsend CA, Juvonen J. Social Identity Complexity, Cross-Ethnic Friendships, and Intergroup Attitudes in Urban Middle Schools. Child development. 2014; 85:709-721.10.1111/cdev.12157 [PubMed: 24032401]

Koshy S. Category crisis: South Asian Americans and questions of race and ethnicity. Diaspora: A Journal of Transnational Studies. 1998; 7:285-320.10.1353/dsp.1998.0013 
Lease AM, Blake JJ. A Comparison of majority-race children with and without a minority-race friend. Social Development. 2005; 14:20-41.10.1111/j.1467-9507.2005.00289.x

Lee, SJ. Unraveling the "model minority" stereotype: listening to Asian American youth. New York: Teachers College Press; 2009.

Levin S, van Laar C, Sidanius J. The effects of ingroup and out-group friends on ethnic attitudes in college: A longitudinal study. Group Processes and Intergroup Relations. 2003; 6:7692.10.1177/1368430203006001013

McPherson M, Smith-Lovin L, Cook JM. Birds of a feather: Homophily in social networks. Annual Review of Sociology. 2001; 27:415-444.10.1146/annurev.soc.27.1.415

Miller RL. Beyond contact theory: The impact of community affluence on integration efforts in five suburban high schools. Youth and Society. 1990; 22:12-34.10.1177/0044118X90022001002

Min, PG., editor. Asian Americans: Contemporary trends and issues. Sage Publications; 2005.

Moody J. Race, school integration, and friendship segragation in America. American Journal of Sociology. 2001; 107:679-716.10.1086/338954

Mouw T, Entwisle B. Residential Segregation and Interracial Friendship in Schools. American Journal of Sociology. 2006; 112:394-441.10.1086/506415

Paolini S, Hewstone M, Cairns Ed, Voci A. Effects of direct and indirect cross- group friendships on judgments of Catholics and Protestants in Northern Ireland: The mediating role of an anxietyreduction mechanism. Personality and Social Psychology Bulletin. 2004; 30:770786.10.1177/0146167203262848 [PubMed: 15155040]

Pettigrew TF. Intergroup contact theory. Annual Review of Psychology. 1998; 49:65-85.10.1146/ annurev.psych.49.1.65

Pettigrew TF. Generalized intergroup contact effects on prejudice. Personality and Social Psychology Bulletin. 1997; 23:173-185.10.1177/0146167297232006

Portes A, Zhou M. The new second generation: Segmented assimilation and its variants among post-1965 immigrant youth. Annals of the American Academy of Political and Social Science. 1993; 530:74-96.

Qin DB, Way N, Mukherjee P. The other side of the model minority story the familial and peer challenges faced by Chinese American adolescents. Youth \& Society. 2008; 39:480506.10.1177/0044118X08314233

Quillian L, Campbell M. Beyond black and white: The present and future of multiracial friendship segregation. American Sociological Review. 2003; 68:540-566.10.2307/1519738

Raudenbush, SW.; Bryk, AS. Hierarchical linear models: Applications and data analysis methods. 2. Thousand Oaks, California: Sage publications, Inc; 2002.

Reis HT, Collins WA. Relationships, human behavior, and psychological science. Current Directions in Psychological Science. 2004; 13:233-237.10.1111/j.0963-7214.2004.00315.x

Rosenbloom SR, Way N. Experiences of discrimination among African American, Asian American, and Latino adolescents in an urban high school. Youth \& Society. 2004; 35:420451.10.1177/0044118X03261479

Rutland A, Abrams D, Levy S. Introduction: Extending the conversation: Transdisciplinary approaches to social identity and intergroup attitudes in children and adolescents. International Journal of Behavioral Development. 2007; 31:417-418.10.1177/0165025407083669

Sani, F.; Bennett, M. Developmental aspects of social identity. In: Bennett, M.; Sani, F., editors. The development of the social self. East Sussex, UK: Psychology Press; 2004. p. 77-100.

Shankar, LD.; Srikanth, R. A part, yet apart: South Asians in Asian America. Temple University Press; 1998.

Shelton JN, Trail TE, West TV, Bergsieker HB. From strangers to friends: The interpersonal process model of intimacy in developing interracial friendships. Journal of Social and Personal Relationships. 2010; 27:71-90.10.1177/0265407509346422

Simpson EH. Measurement of diversity. Nature. 1949; 163:688-688.10.1038/163688a0

Snyder, TD.; Dillow, SA. Digest of Education Statistics, 2012. NCES 2014-015. National Center for Education Statistics; 2013. 
Stephan WG, Stephan CW. Intergroup anxiety. Journal of Social Issue. 1985; 41:157-175.10.1111/j. 1540-4560.1985.tb01134.x

Tropp LR, Pettigrew TF. Differential relationships between intergroup contact and affective and cognitive dimensions of prejudice. Personality and Social Psychology Bulletin. 2005; 31:11451158.10.1177/0146167205274854 [PubMed: 16000274]

Tummala-Narra P, Alegria M, Chen CN. Perceived discrimination, acculturative stress, and depression among South Asians: Mixed findings. Asian American Journal of Psychology. 2012; 3:316.10.1037/a0024661

Umaña-Taylor AJ, Quintana SM, Lee RM, Cross WE, Rivas-Drake D, Schwartz SJ, Seaton E. Ethnic and racial identity during adolescence and into young adulthood: An integrated conceptualization. Child development. 2014; 85:21-39.10.1111/cdev.12196 [PubMed: 24490890] 


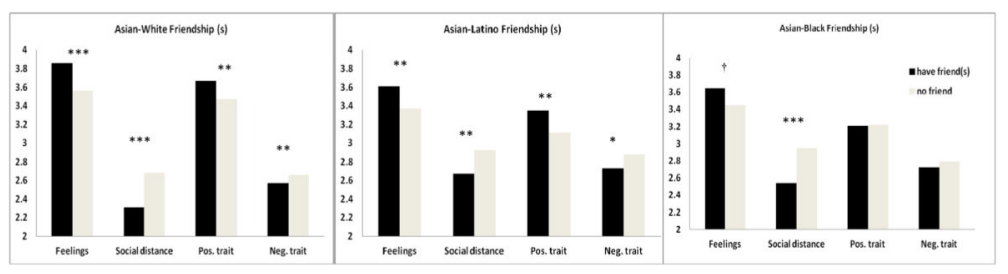

Figure 1.

Existence of at least one out-group friend and attitudes toward the out-group.

Note. Pos. trait = positive trait evaluations; Neg. trait = negative trait evaluations. ${ }^{\dagger} p<.10,{ }^{*} p<.05,{ }^{* *} p<.01,{ }^{* * *} p<.001$. 


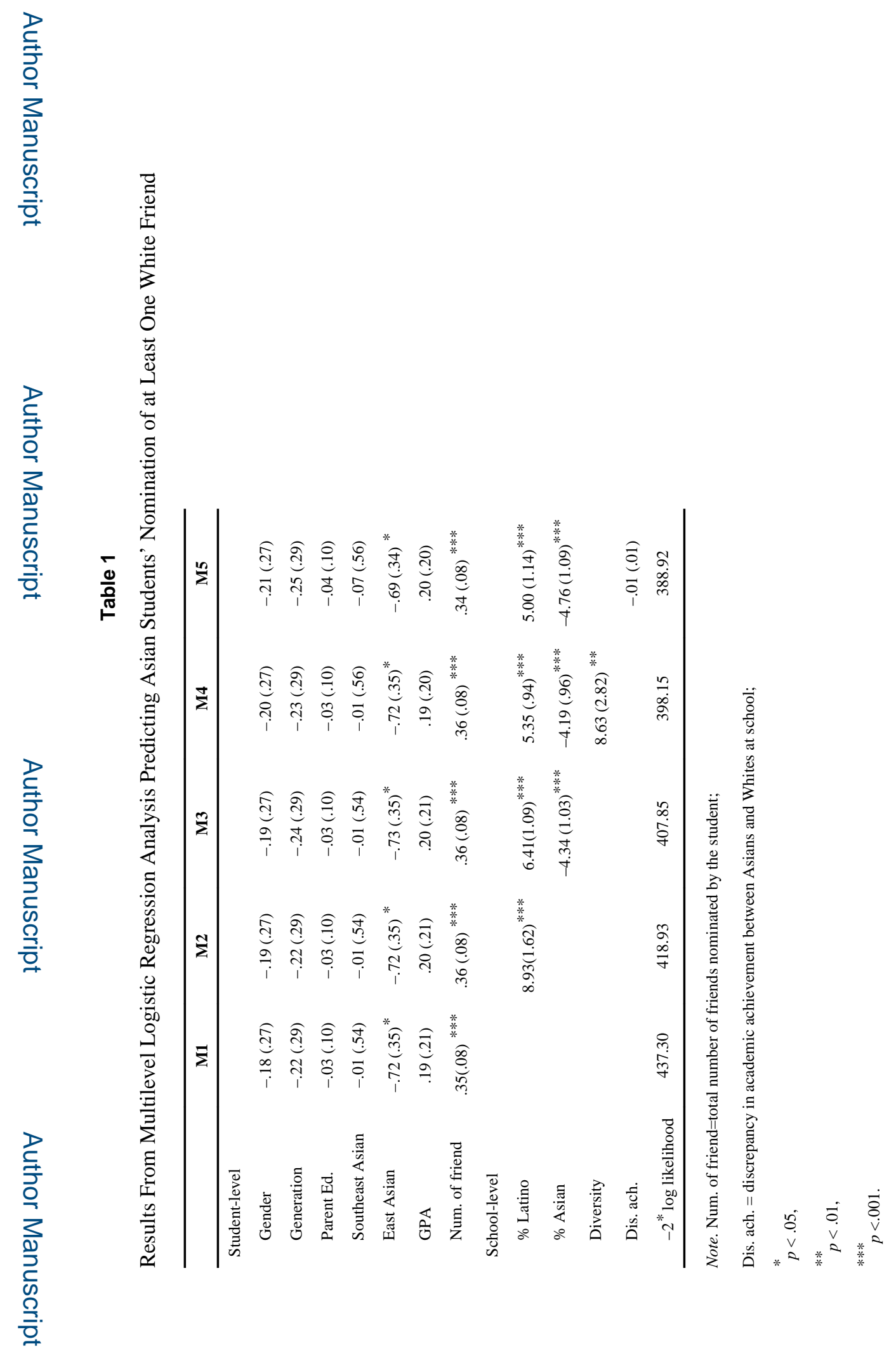

Child Dev. Author manuscript; available in PMC 2016 May 01. 


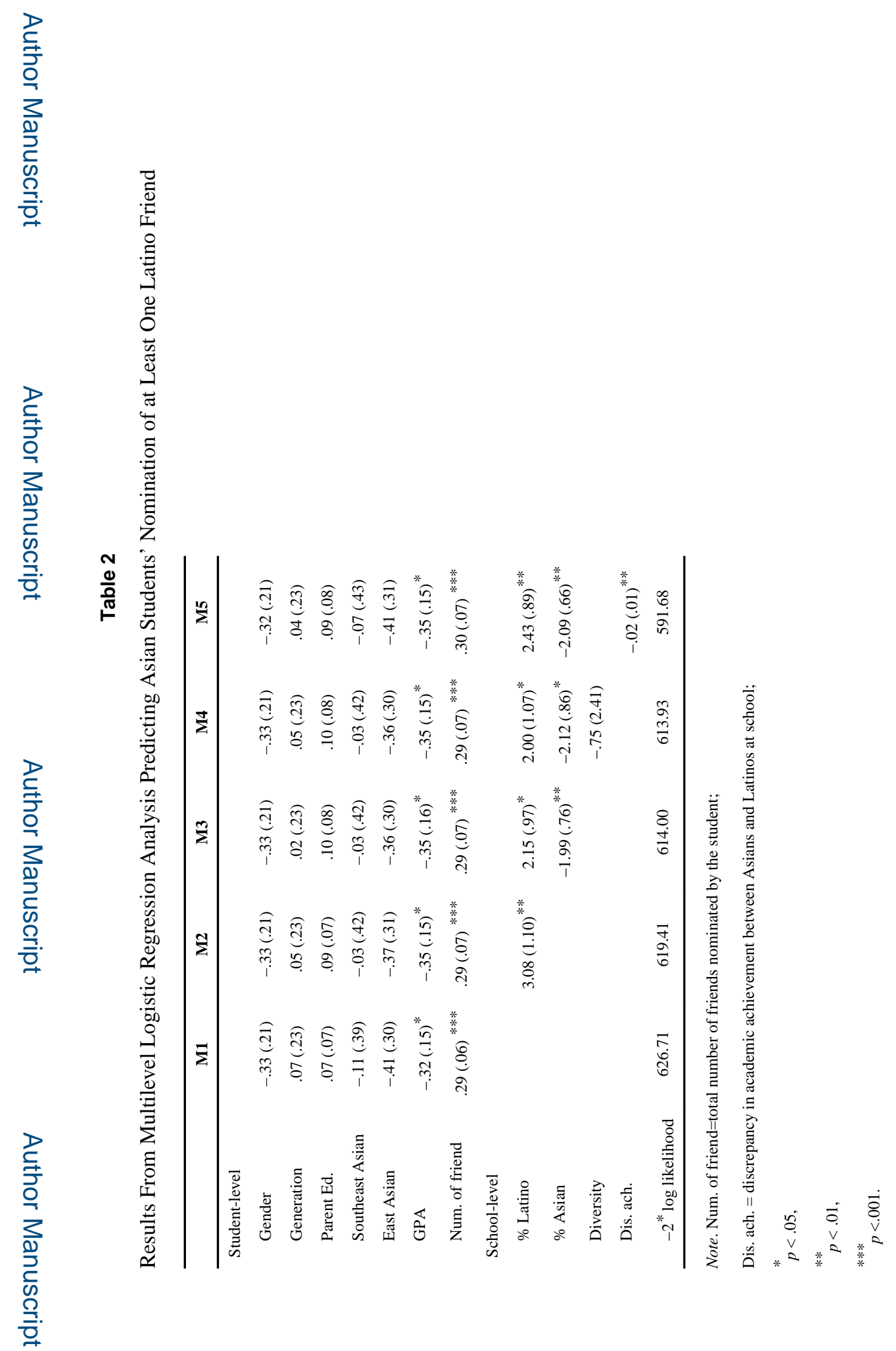

Child Dev. Author manuscript; available in PMC 2016 May 01. 


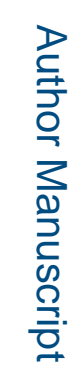

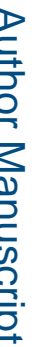

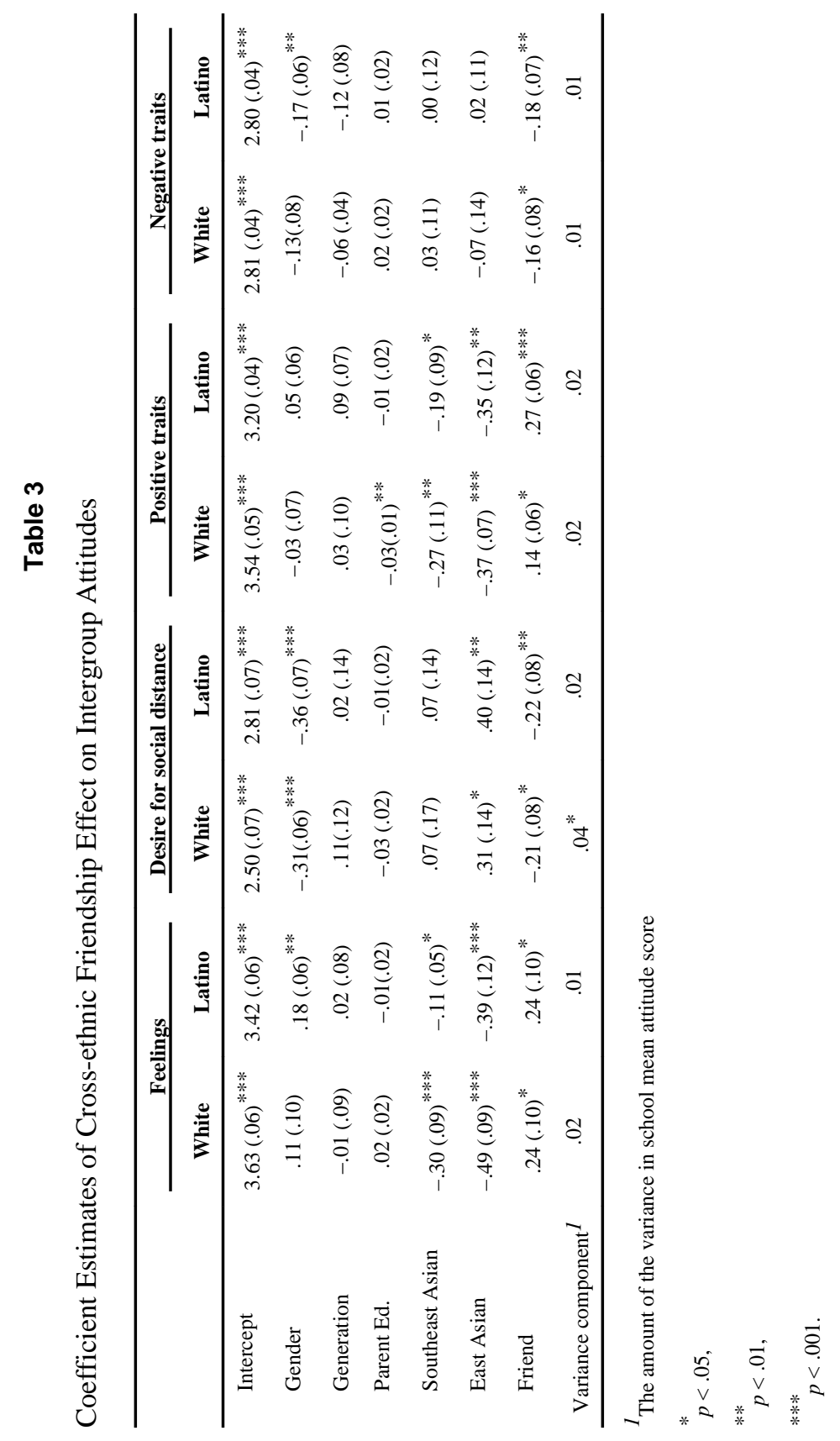

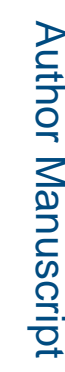

ב

$$
\text { 을 }
$$




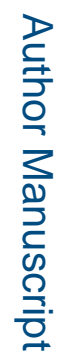

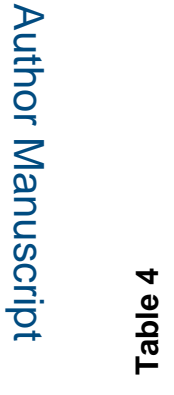

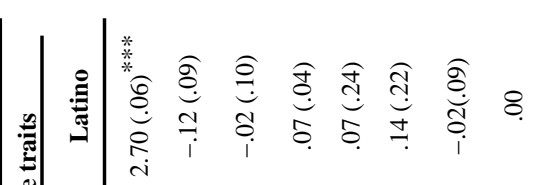

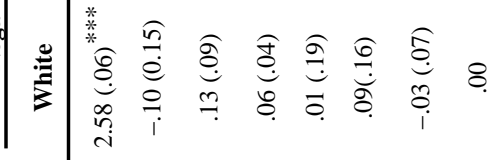

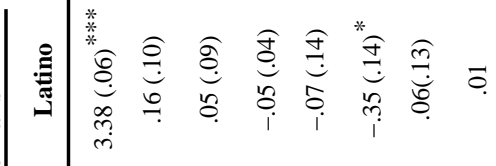

*

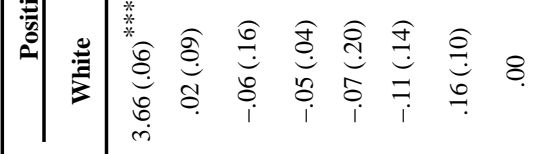
龸 $|=|$

言

更

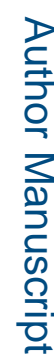

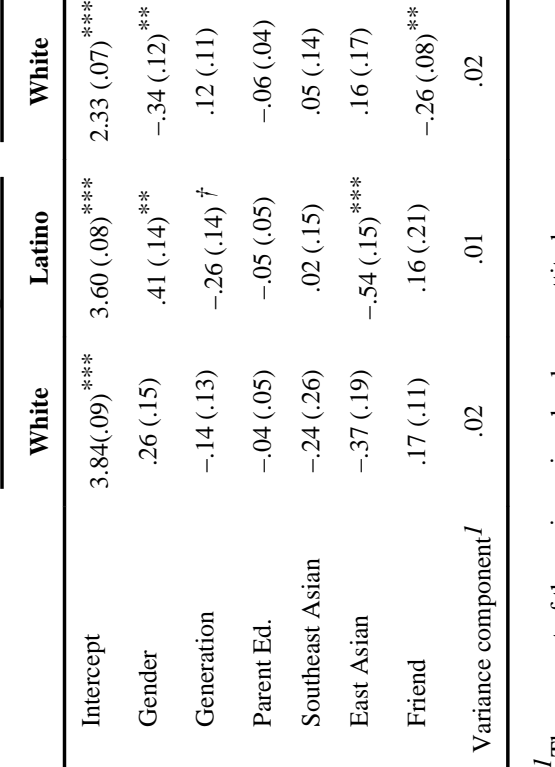

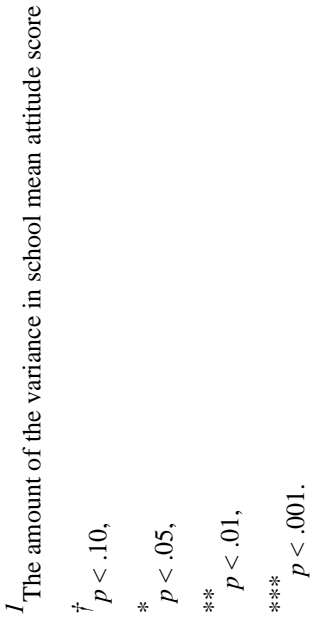

Child Dev. Author manuscript; available in PMC 2016 May 01. 


\section{로을}

ב

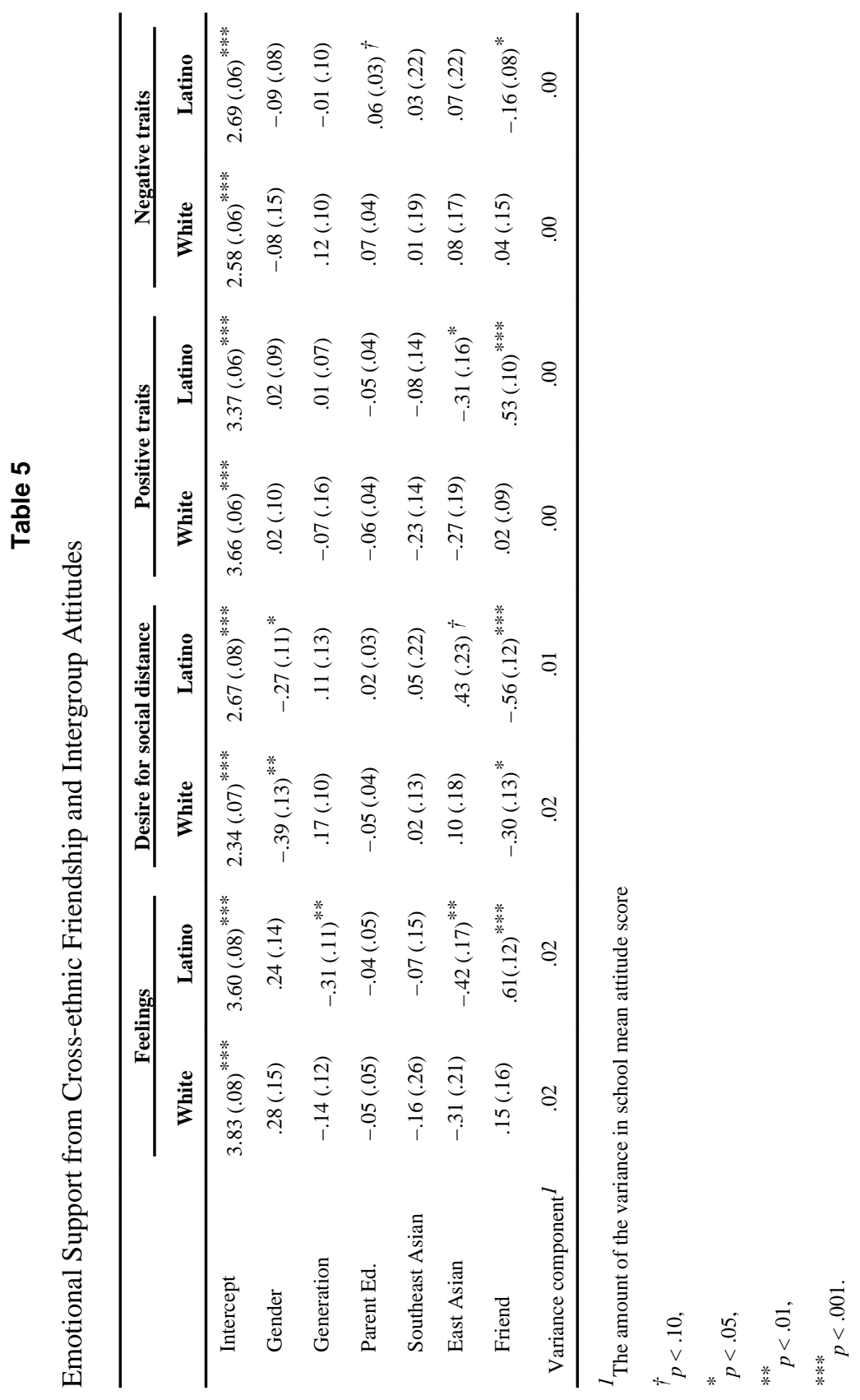

를

Child Dev. Author manuscript; available in PMC 2016 May 01. 